\title{
'Quality of life' after therapy in rats with myocardial infarction: dissociation between hemodynamic and behavioral improvement
}

\author{
Regien G. Schoemaker ${ }^{\text {a, }}{ }^{\text {, Ed A.J. Kalkman }}{ }^{\text {a }}$, Jos F.M. Smits ${ }^{\text {b }}$ \\ a Department of Pharmacology, Faculty of Medicine and Health Sciences, Erasmus University Rotterdam, Rotterdam, Netherlands \\ ${ }^{\mathrm{h}}$ Cardiovascular Research Institute Maastricht, Department of Pharmacology, University of Limburg, Maastricht, Netherlands
}

Received 16 February 1995; revised 9 November 1995; accepted 14 November 1995

\begin{abstract}
Rats with myocardial infarction provide a clinically relevant model for hemodynamic and survival studies. Moreover, behavioral changes in this model, i.e. increased anxiety and reduced interest in environment and social interactions, mimic aspects of the reduced quality of life of patients. In the present study, we investigated whether pharmacological treatment that is known to improve hemodynamics and prognosis could also affect the behavioral changes associated with quality of life. Rats with 3-week-old infarcts were treated with intermittent dobutamine ( $1 \mathrm{mg} / \mathrm{kg}$ i.p., twice daily) or captopril $(2 \mathrm{~g} / 1$ in drinking water). After 2 weeks of treatment, when from previous studies hemodynamics are expected to be restored, behavioral tests were performed. In the free exploration test, which primarily evaluates exploratory behavior, dobutamine normalized the reduced interest in the environment. In the standard open field and social interaction tests, which also include an anxiety component, the beneficial effects of dobutamine were not observed. In contrast, captopril normalized all behavioral changes that indicated increased anxiety. In conclusion, the expected similar hemodynamic improvement with dobutamine and captopril treatment resulted in improvement of different aspects of the changed behavior of rats with myocardial infarction, indicating that there is no direct relationship between hemodynamics and quality of life. The behavioral tests used, in combination with our previously described functional hemodynamic measurements, could provide a new basis for evaluating the effects of therapy on hemodynamic function as well as the quality of life.
\end{abstract}

Keywords: Myocardial infarction; Quality of life; (Rat); Anxiety; Exploration; Social behavior

\section{Introduction}

Treatment of chronic myocardial infarction is directed at improving the hemodynamic state of the patient (Guyatt, 1986) and at interacting with the hypertrophy and remodelling, to delay progression of heart failure (Lamas and Pfeffer, 1990). While the former leads to relief of symptoms of congestion, the latter is aimed at improving prognosis (Pfeffer et al., 1992).

However, after extensive revalidation programs and pharmacological treatment, patients suffering from a healed myocardial infarction still have more functional difficulties in their normal daily life than their hemodynamic state would suggest (Oldridge et al., 1991). This reduced 'quality of life', including anxiety/depression, loss of interest

\footnotetext{
* Corresponding author. Department of Pharmacology, Erasmus University Rotterdam, P.O. Box 1734, NL-3000 DR Rotterdam, Netherlands. Tel.: (31) (0)10 4087530/47; fax: (31) (0)10 4366839 .
}

in environment and in social interactions, sexual difficulties and sleep disturbances (Olsson et al., 1986; Bulpitt and Fletcher, 1988; Barnett, 1991; Oldridge et al., 1991; Rector and Cohn, 1992), has become a serious target for therapy now. Moreover, the growing population of older people who are at risk for heart failure after surviving myocardial infarction, due to improved medical care, requires that therapy should be directed not only at increasing life expectancy, but also the quality of life.

Rats with experimental myocardial infarction have proven to provide a clinically relevant model for hemodynamic (Pfeffer et al., 1985; Schoemaker et al., 1990, 1991a), humoral (Inoue et al., 1987; Hodsman et al., 1988), structural (Van Krimpen et al., 1991; Smits et al., 1991, 1992) and survival studies (Pfeffer et al., 1987; Sweet et al., 1988). In addition, we have recently reported that these rats exhibit behavioral changes that mimic aspects of the decreased quality of life of patients with myocardial infarction, including increased anxiety/depression, and loss of interest in the environment and social 
interactions (Schoemaker and Smits, 1994).

The aim of the present study was to investigate whether pharmacological treatment (dobutamine or captopril) that improves hemodynamic function in rats with chronic myocardial infarction also has beneficial effects on their behavioral pattern, which could be considered to reflect a reduced 'quality of life'. In our previous studies, we have shown that 2 weeks' intermittent treatment with dobutamine, a sympathomimetic (Schoemaker et al., 1991b), or captopril, an angiotensin I converting enzyme inhibitor, (Schoemaker et al., 1991a) improved hemodynamics and cardiac function. Moreover, captopril also improved prognosis in this model (Pfeffer et al., 1987).

\section{Material and methods}

\subsection{Animals}

Male Wistar rats $( \pm 270 \mathrm{~g}$, Winkelman, Borchen, Germany or T.N.O. Zeist, Netherlands) were used in this study. Before surgery the rats were housed in groups of $3-4$, whereas after surgery the rats were housed 2-3 with infarct and sham rats randomly divided. The rats had free access to standard laboratory chow and tap water in a reversed $12 \mathrm{~h}$ light/dark cycle (lights off from 9 a.m. to 9 p.m.).

\subsection{Myocardial infarction}

Rats were subjected to either coronary artery ligation or sham operation, using a modification (Schoemaker et al., 1990, 1991a) of the method of Fishbein et al. (1978). Briefly, animals were anesthetized with pentobarbital (60 $\mathrm{mg} / \mathrm{kg}$ i.p.) and the trachea was intubated (PE-240). The skin overlying the fourth intercostal space was cut, and underlying muscles were separated and kept aside. The thorax was opened after positive pressure respiration was started and the heart was carefully pushed to the left by applying pressure to the right side of the thorax. A silk (6-0) suture was looped under the left descending coronary artery near the origin of the pulmonary artery. In sham animals the suture was looped through the myocardium, right next to the coronary artery. When the heart was returned to its normal position, the suture was closed and the ribs were pulled together with 3-0 silk. The muscles were returned to their normal position and the skin was closed.

\subsection{Treatment}

Treatment was started 3 weeks after myocardial infarction, that is after the healing period (Fishbein et al., 1978), and was continued for the rest of the experimental period (7-8 weeks after surgery). Dobutamine was given as i.p. injections of $1 \mathrm{mg} / \mathrm{kg}$ (injected volume $1 \mathrm{ml} / \mathrm{kg}$ ) twice daily. Since dobutamine i.p. caused hemodynamic activation, an effect which completely disappeared within 45 $\mathrm{min}$, the two injections were given $90-180 \mathrm{~min}$ apart, resulting in at the most stimulation for 90 min per $24 \mathrm{~h}$. For further validation of this treatment, see Schoemaker et al. (1991b). Control rats were injected twice daily with saline $(1 \mathrm{ml} / \mathrm{kg})$ to check for effects of this type of daily handling. Similar to the hemodynamic study (Schoemaker et al., 1991b), behavioral tests were performed at least $18 \mathrm{~h}$ after the last injection, a time point at which no dobutamine is present in the circulation, but hemodynamic improvement was present.

Captopril was administered in the drinking water (2 g/1) (Pfeffer et al., 1985, 1987), and not by using osmotic minipumps, as described in our previous studies (Schoemaker et al., 1991a; Van Krimpen et al., 1991), since this would have required three extra operations to implant and exchange pumps, shortly before or during behavioral tests. Moreover, the results from hemodynamic studies with anesthetized rats, using captopril in the drinking water (Pfeffer et al., 1985, 1987), were comparable to ours in conscious rats with captopril administered with osmotic minipumps (500 $\mu \mathrm{g} / \mathrm{kg} \cdot \mathrm{h}$; Schoemaker et al., 1991a). In addition, the $2 \mathrm{~g} / 1$ captopril in the drinking water improved survival (Pfeffer et al., 1987). Therefore, it seems feasible to expect that the hemodynamics of the treated rats were improved at the time of behavioral testing.

Since rats were socially housed, individual water (containing captopril) intake was not determined. However, on average rats drank $25-30 \mathrm{ml}$ per day, resulting in $50-60$ $\mathrm{mg}$ captopril per rat per day. The bioavailability of oral dietary captopril in rats is $29 \%$ (Singhvi et al., 1981) and docs not change during chronic trcatment. The average effective dose of captopril would be then $15 \mathrm{mg}$ per day per rat.

\subsection{Behavioral tests}

Starting after 2 weeks' treatment, behavioral tests were performed during the dark period of the light/dark cycle, using an open field cage $(100 \times 100 \times 30 \mathrm{~cm}$, floor surface divided into 36 squares, and illuminated with $40 \mathrm{~W}$ red light). Equivalent to the functional difficulties in their normal daily life of patients, this set-up and tests were chosen to match closely the 'normal daily life' of laboratory rats; being moved to other cages and mixing with other rats. Since pilot studies indicated no significant difference in exploratory behavior in the open field following the very first exposure, all rats were allowed to explore the open field during a $5 \mathrm{~min}$ period, $24 \mathrm{~h}$ prior to the first test. The following tests were performed twice, with at least $24 \mathrm{~h}$ in between:

\subsubsection{Free exploration}

This test is a modified version of the free exploration test as described by Knardahl and Sagvolden (1979), and is 
more directed to pure exploration than the standard open field test is, because the latter also includes an anxiety component. The rat has a choice whether or not to explore a new area from its own familiar home cage. To create a situation that is as little aversive as possible, the rat was allowed $5 \mathrm{~min}$ exploration of the open field just prior to the test. The rat was placed in the middle of the open field cage and left to explore this new area for $5 \mathrm{~min}$. Then, it was returned to its home cage (from which the other rat(s) had been removed) and placed, with this home cage left open, into the open field again. The percentage of time spent resting and grooming in the home cage, exploration (digging, sniffing, and locomotion combined with sniffing) inside the home cage, and exploration of the area outside (the edges of the cage and the space above the cage) as well as the total time before the rat climbed out of its cage into the open field (with a maximum of $10 \mathrm{~min}$ ) was measured (latency), and the test was terminated. The ratio of exploration outside/resting, grooming and exploration inside was calculated as activity outside/inside.

For infarcted rats, climbing out of their cage may be hampered by physical limitations. To check whether the infarcted and sham rats were physically capable of climbing out of their cages, we placed their cage-mate(s) in a closed separate cage right next to the home cage with the experimental rat and determined whether the experimental rat climbed out of its cage. For the captopril treated rats and their respective sham and infarct controls, the time before leaving the home cage was measured.

\subsubsection{Forced exploration}

This test is basically a standard open field test, analyzed in three different ways. Since it was not possiblc to perform the different analyses at the same time, in three separate sessions (twice each) of $5 \mathrm{~min}$, after the rat was placed in the middle of the open field, we measured (a) percentage of time spent in the corner areas, along the walls, or in the middle part, (b) locomotor activity, by counting the number of line crossings per $5 \mathrm{~min}$, and (c) percentage of time spent on a variety of behavioral elements, namely, resting, sniffing *, sniffing with walking *, walking only ${ }^{*}$, exploration of the walls ${ }^{*}$, rearing ${ }^{*}$, scanning, and grooming. The total time spent on exploration was determined as the total for the behaviors marked with *.

\subsubsection{Social interest}

The rat was placed in the middle of the open field and allowed to explore it for $5 \mathrm{~min}$. Then a young adult male rat (at least $150 \mathrm{~g}$ less in body weight) was introduced as far as possible from the experimental rat (Bluthé et al., 1992). The percentage time spent on different elements of social behavior including fixation, moving towards, social investigation, and aggression/defence (Lehman and Adams, 1977; Koolhaas et al., 1983), as well as non-social elements including resting, moving away, grooming and exploration of the open field itself, was registered during a 5-min period. Total social behavior was determined as time spent on fixation, moving towards, and social investigation.

The two free exploration tests and social interaction tests were never performed on two consecutive days. Moreover, the 5-min habituation prior to these tests was used to score one of the three parameters for the forced exploration test, since the setting was exactly the same.

After completion of the experiments, rats were anesthetized with pentobarbital and the hearts were excised. Hearts were washed in saline, vessels and atria were removed and the ventricles were weighed. The presence of extensive left ventricular infarctions was verified visually.

\subsection{Data analysis}

All tests were performed twice, and the average result of the two tests was calculated for each rat. Since infarcts of less than $20 \%$ of the left ventricle have no hemodynamic consequences (Schoemaker et al., 1991a), data from rats with visually determined small infarcts were excluded from further analysis. Since the behavior during the tests of rats receiving daily injections of saline, as control for dobutamine treatment, and the not specifically handled rats, as control for captopril treatment, was not different, data obtained from these control groups were pooled. Data for groups of rats are presented as means \pm S.E.M. Differences between groups in percentage time spent on certain behavioral elements were analyzed using the non-parametric Kruskal-Wallis test, followed by post-hoc Tukey test (percentages time spent on different behavior within one test are not independent). Differences in body weight and heart weight, as well as the number of crossings in the open field and number of visits into the middle area, were

Table 1

Characterization of experimental groups

\begin{tabular}{lcccc}
\hline & Sham & Infarct & Infarct + dobutamine & \multicolumn{2}{c}{ Infarct + captopril } \\
$n$ & 9 & 12 & 10 & 8 \\
\hline Start weight (g) & $269 \pm 3$ & $271 \pm 4$ & $270 \pm 3$ & $270 \pm 3$ \\
Body weight (g) & $385 \pm 9$ & $399 \pm 10$ & $387 \pm 13$ & $349 \pm 11^{\mathrm{b}}$ \\
Heart weight (mg) & $1148 \pm 32$ & $1557 \pm 64^{\mathrm{a}}$ & $1505 \pm 63$ & $1070 \pm 57^{\mathrm{b}}$ \\
Heart/body weight & $3.0 \pm 0.1$ & $4.0 \pm 0.2^{\mathrm{a}}$ & $3.9 \pm 0.2$ & $3.1 \pm 0.2^{\mathrm{b}}$ \\
\hline
\end{tabular}

a Significant difference between rats with infarction and sham rats. ${ }^{b}$ Significant difference between non-treated and treated rats with infarction. 
tested using one-way analysis of variances, with post-hoc test according to Dunnett. Relationships between results of different tests were analyzed using linear regression analysis. Differences are regarded as statistically significant if $P<0.05$.

\section{Results}

\subsection{General}

Coronary artery ligation resulted in transmural infarctions, except for small ones, in the free wall of the left ventricle. The overall mortality was $20 \%$ within the first $24 \mathrm{~h}$. Four rats were excluded from analysis because of too small infarctions; two from the non-treated group with infarction, and one each from the captopril- and dobutamine-treated groups. The general characteristics of the experimental groups are presented in Table 1. Whereas body weights were comparable at the start of the protocol, 7-8 weeks later captopril treated rats had significantly lower body weights than the other groups. Heart weight was significantly increased after myocardial infarction and was normalized by captopril, but not by dobutamine treatment. Although both body weight and heart weight were reduced by captopril, the heart weight/body weight ratio was normalized to sham values in captopril-treated rats with myocardial infarction.

Despite the fact that the behavioral tests were performed over an extended period of time (1.5-2 weeks), with repeated daily exposure to the same setting, no signs of habituation or reduced motivation were observed (time spent on exploration being $81 \pm 4$ and $79 \pm 3 \%$; time spent in the middle area of the open field $15 \pm 2$ and $17 \pm 2 \%$ in the first and second tests, respectively, for all rats together. No differences between groups were observed.

\subsection{Free exploration (Fig. 1)}

Sham rats spent little time resting and grooming but immediately started exploration in- and outside their cage. On average, these rats left their own cage in about $100 \mathrm{~s}$, to explore the new environment. Rats with myocardial infarction spent significantly more time resting and grooming in their own cage. This occurred at the expense of exploration of the area outside their home cage, since exploration inside their home cage was similar to that of sham rats. Rats with myocardial infarction took about 160 $s$ before they left their home cage (Fig. 1). The ratio activity outside/inside the home cage before climbing out was significantly less in the rats with infarction $(2.3 \pm 0.3$ compared to $3.6 \pm 0.5$ ). Dobutamine treatment significantly increased the time spent exploring the area outside the home cages, without the rats leaving the cage earlier than the non-treated infarcted rats did. The increased exploration outside the home cage occurred at the expense of

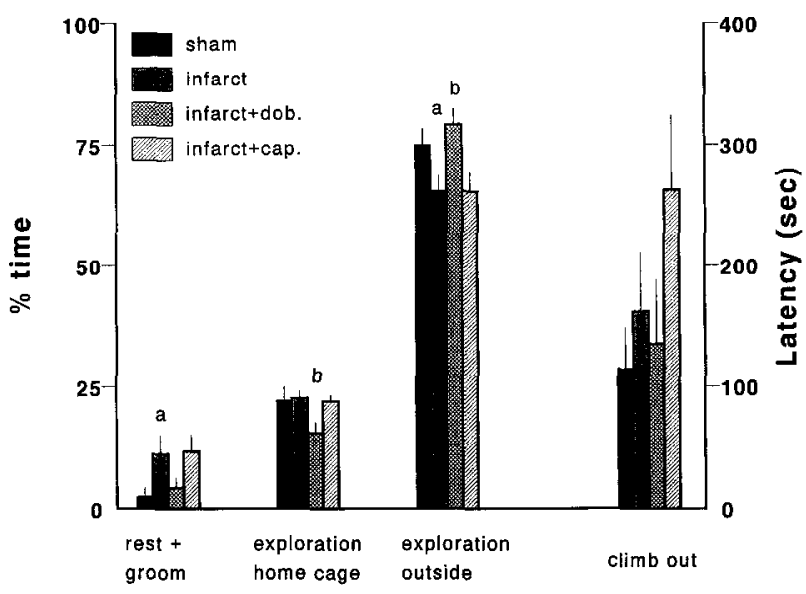

Fig. 1. Time spent on different elements of behavior by sham, non-treated, and dobutamine- (dob.) and captopril- (cap.) treated rats with myocardial infarction, and latency to leave the home cage in the 'free exploration test'. "Significant difference between rats with infarction and sham rats. ${ }^{b}$ Significant difference between non-treated and treated rats with myocardial infarction.

both resting and grooming (not significant) and exploration inside the home cage, increasing the outside/inside ratio significantly (to $4.1 \pm 0.7$ ). In contrast, captopril had no effect on the percentage time spent on the different behavioral elements (activity outside/inside $2.4 \pm 0.5$ ). Total time before leaving the home cage was more than $50 \%$ longer than for non-treated rats with infarction. Because of the high variability of the latency times, no statistically significant differences were found.

In the situation with the cage-mate of the experimental rat in an adjacent cage, all experimental rats immediately started to climb out of their cage. In the captopril-treated and control groups, we measured this latency. All rats left their home cage within $1 \mathrm{~min}$, with no statistical differences between groups (mean values: sham $49 \pm 16 \mathrm{~s}$; infarct $27 \pm 8 \mathrm{~s}$; infarct + captopril $38 \pm 6 \mathrm{~s}$ ).

\subsection{Forced exploration (Figs. 2 and 3)}

\subsubsection{Spatial distribution and locomotor activity}

Sham rats spent about $85 \%$ of the time in the corners and along the walls, equally divided between the two areas. The middle part was only incidentally visited. Infarcted rats significantly preferred the corners of the open field, at the expense of both the middle ( $40 \%$ less) and the wall areas (20\% less). Although the difference between rats with infarction and sham rats in percentage time spent at the middle part did not reach statistical significance, the number of visits into the middle part was significantly lower for infarcted rats $(8.7 \pm 0.8$ compared to $12.4 \pm 1.8)$.

The number of line crossings, as a measure for locomotion, was almost $200 / 5 \mathrm{~min}$ for sham rats, and was significantly reduced to just above 100 in infarcted rats (Fig. 2).

Dobutamine treatment had no effect on any of the 


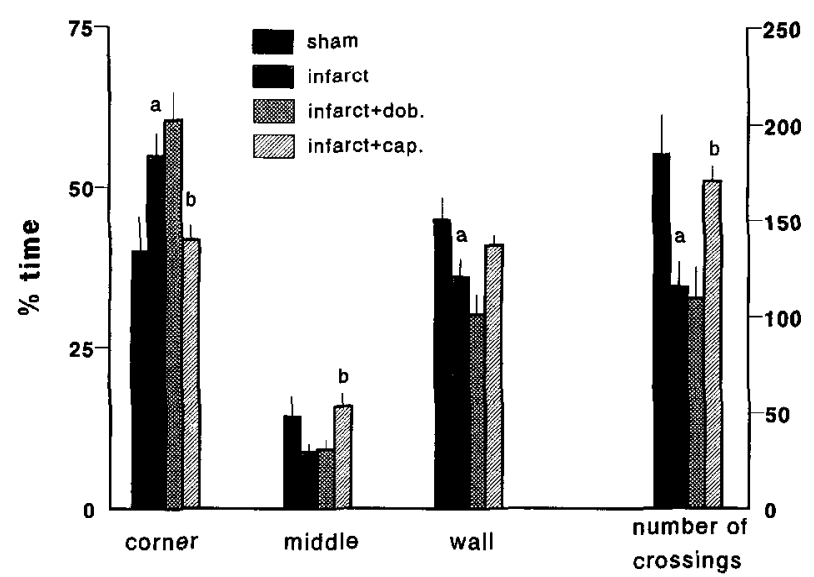

Fig. 2. Time spent in different areas of the open field by sham, non-treated, and dobutamine- (dob.) and captopril- (cap.) treated rats with myocardial infarction, and number of line-crossings during $5 \mathrm{~min}$ in the 'forced exploration test'. ' Significant difference between rats with infarction and sham rats. 'Significant difference between non-treated and treated rats with myocardial infarction.

above mentioned parameters, whereas captopril significantly affected all infarction induced changes towards sham values (except for time spent along the wall) (Fig. 2).

\subsubsection{Exploratory behavior}

Rats with infarction spent significantly less total time on exploration compared to sham rats $(75 \pm 2$ compared to $88 \pm 2 \%$ of time). A detailed presentation of the different behavioral elements showed that rats with infarction spent significantly more time resting and scanning, anxious exploration, at the expense of walking and rearing. Sniffing and exploration of the wall did not change. Dobutamine had no significant effects on either total exploration time $(74 \pm 5 \%)$ or its distribution over the different behavioral elements (Fig. 3). Captopril treatment also did not change total time spent on exploration ( $76 \pm 4 \%)$, but the compo-

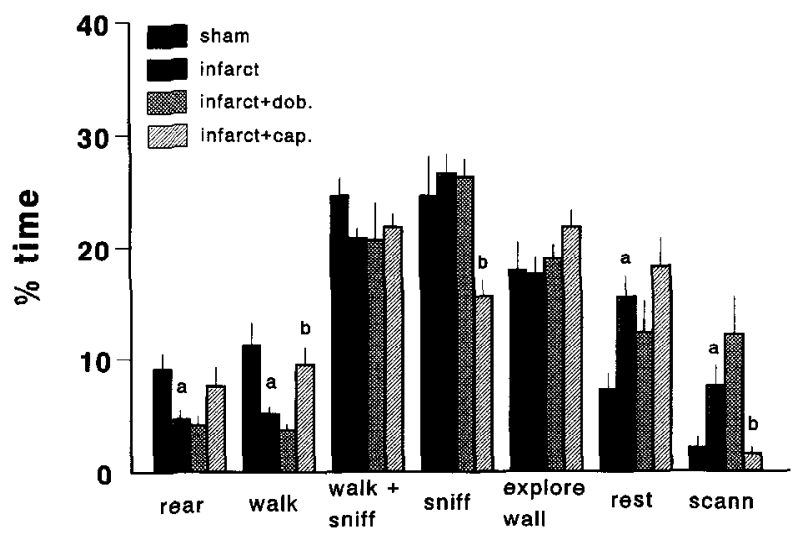

Fig. 3. Time spent on different elements of exploratory behavior by sham, non-treated, and dobutamine- (dob.) and captopril- (cap.) treated rats with myocardial infarction in the 'forced exploration test'. " Significant difference between rats with infarction and sham rats. ${ }^{b}$ Significant difference between non-treated and treated rats with myocardial infarction.

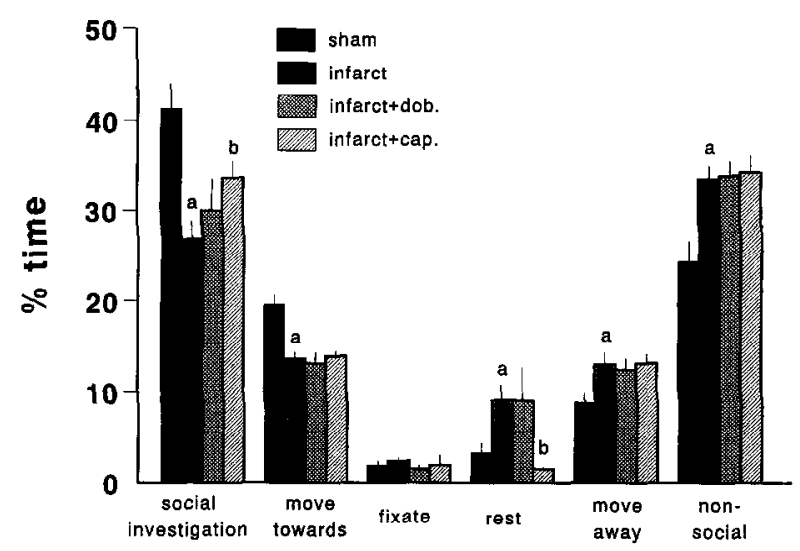

Fig. 4. Time spent on different elements of social behavior towards a young unfamiliar male rat by sham, non-treated, and dobutamine- (dob.) and captopril- (cap.) treated rats with myocardial infarction. ${ }^{a}$ Significant difference between rats with infarction and sham rats. ${ }^{b}$ Significant difference between non-treated and treated rats with myocardial infarction.

sition underwent significant changes: sniffing and scanning significantly decreased, whereas walking and rearing (although not statistically significant) increased. Resting was not affected.

\subsection{Social interest (Fig. 4)}

Sham rats spent $63 \pm 3 \%$ of the time on social behavior towards the young male, whereas for rats with infarction this was significantly reduced to $44 \pm 3 \%$. A detailed presentation of the elements of social behavior is shown in Fig. 4. The active elements of social behavior, such as moving towards and social investigation, were reduced in rats with infarction, whereas more resting and non-social behavior was displayed. Moreover, rats with infarction showed more active avoidance of social interactions by moving away.

Dobutamine treatment had no effects on total social behavior $(45 \pm 4 \%)$ nor on any of its elements (Fig. 4). Captopril treatment also had no significant effect on total social behavior $(49 \pm 3 \%)$. However, the time spent on social investigation was significantly increased by captopril compared to that of non-treated rats with infarction (Fig. 4). This occurred at the expense of resting behavior.

\subsection{Correlations between test results}

Major parameters from the different tests, including activity outside/inside from the free exploration test; total exploration, corner preference, and number of crossings from the forced exploration test; and the total social behavior of the social interaction test, were analyzed for nontreated rats, and for all rats (Table 2). It revealed that most parameters from different tests were interrelated, with the exception of the activity outside/inside of the free exploration test. For non-treated rats the results from the free 
Table 2

Correlation coefficients of statistically significant correlations between parameters of different tests

\begin{tabular}{lcccccc}
\hline & expl. & out/in & cross & comer & social & hw/bw \\
\hline expl. & & 0.40 & 0.41 & -0.47 & 0.52 & -0.42 \\
out/in & 0.53 & & ns & ns & ns & ns \\
cross & 0.61 & 0.55 & & -0.62 & 0.32 & 0.59 \\
corner & $n s$ & -0.49 & -0.62 & & -0.43 & 0.54 \\
social & 0.65 & $n s$ & $n s$ & $n s$ & & -0.33 \\
hw/bw & -0.67 & $n s$ & -0.69 & 0.68 & -0.58 & \\
\hline
\end{tabular}

Italics: values for nontreated rats. Normal: values for all rats. expl.: total exploration; out/in: activity outside/inside home cage; cross: number of crossings; corner: corner preference; social: total social behavior; hw/bw: heart weight/body weight ratio; ns: not statistically significant.

exploration and forced exploration tests were related: rats with high outside/inside ratios showed more exploration, more crossings, and lower corner preference in the forced exploration test, but no relation was found with the results of the social interaction test. For all rats together, the result of the free exploration test was only correlated with total exploration in the forced exploration test.

All parameters, except outside/inside ratio, were correlated with heart weight/body weight ratio.

\section{Discussion}

\subsection{Quality of life in myocardial infarcted patients; effects of captopril and dobutamine}

In addition to the hemodynamic changes following myocardial infarction, patients experience major psychological alterations, resulting in a generally reduced sense of well being. This reduced quality of life is more pronounced than the hemodynamic alterations would suggest (Oldridge et al., 1991), and includes anxiety/depression, loss of interest in environment and social interactions, sexual difficulties, and sleep disturbances (Olsson et al., 1986; Bulpitt and Fletcher, 1988; Barnett, 1991; Oldridge et al., 1991; Rector and Cohn, 1992).

Captopril improves the hemodynamics (Lamas and Pfeffer, 1990) and life expectancy (Pfeffer et al., 1992) of patients with heart failure. The suggestion that captopril also may influence mental function was already raised in 1986, where it was reported to induce 'a sense of well being' (Croog et al., 1986). Now there is growing evidence that captopril improves the quality of life of patients with hypertension (Breckenridge, 1991; Testa et al., 1993) or heart failure (Just et al., 1993). This could not be attributed directly to peripheral angiotensin converting enzyme (ACE) inhibition, and consequent hemodynamic changes, since, despite the similar effects of enalapril on hemodynamics and prognosis (Consensus Trial Study Group, 1987), the effects of enalapril on quality of life are less conclusive (Blumenthal et al., 1990; Rector et al., 1993; Testa et al., 1993). The different effects may be associated with differ- ent penetration or binding in the central nerveus system (Cushman et al., 1989).

Chronic intermittent dobutamine treatment for heart failure was of high interest during the eighties, because of the sustained improvement attained (Leier et al., 1982; Liang et al., 1984; Roffman et al., 1985): To our knowledge, no data are available about effects on long-term prognosis or quality of life. Increased anxiety may occur, but is associated with acute administration (Mertes et al., 1993). Nevertheless, it is not known whether effects on quality of life are related to hemodynamic improvement. In the present study, we addressed this question in an animal model for heart failure.

\subsection{Quality of life in the model of myocardial infarcted rats}

Rats with coronary artery ligation provide a clinically relevant model for the consequences of myocardial infarction on hemodynamics (Schoemaker et al., 1991a; Pfeffer et al., 1985) and survival (Pfeffer et al., 1987; Sweet et al., 1988). Decreased cardiac output and left ventricular function, as well as mortality, are related to infarct size. Moreover, we have recently reported behavioral changes in this model, changes that mimic aspects of the reduced quality of life of patients (Schoemaker and Smits, 1994). Behavioral tests showed reduced interest in environment, enhanced anxiety/depression, and lower social interest in rats with myocardial infarction. The mechanisms underlying the behavioral changes in rats with infarction are not known, but may include changes in neurotransmitter levels (Olson and Morgan, 1982) as well as interleukin-1 associated 'sickness behavior' (Dantzer et al., 1991; Bluthé et al., 1992). In rats with chronic myocardial infarction, increased metabolism in the paraventricular hypothalamus and locus coeruleus has been shown (Patel et al., 1993).

\subsection{Effects of therapy}

In one of our previous studies on the hemodynamics of rats with infarction, we have shown that captopril treatment, started after the healing period (3-5 weeks after infarction), could restore hemodynamics and cardiac function (Schoemaker et al., 1991a). Moreover, captopril therapy also increased long-term survival in these rats (Pfeffer et al., 1987). Intermittent dobutamine treatment during the same period after infarction (3-5 weeks) resulted in sustained hemodynamic improvement, comparable to that after captopril treatment (Schoemaker et al., 1991b). Effects on survival are not known. In the present study we investigated the effects of these two types of treatment on the behavioral changes after myocardial infarction. Behavioral tests werc started after 2 weeks of treatment, the timc point at which the above studies reported hemodynamic improvement. Therefore, in this study the hemodynamics of the treated rats are expected to be improved. 
Reduced interest in the environment was studied in the free exploration test. Non-treated rats with infarction showed reduced interest in the new environment, as indicated by decreased exploration of the area outside the home cage. Treatment with the angiotensin converting enzyme inhibitor captopril did not affect this behavior and even further prolonged the time before the rat would climb out of its cage. In contrast, dobutamine treatment restored the interest in the environment, as indicated by the increased exploration of the area outside the home cage at the expense of all activity inside the home cage. The major effect of intermittent dobutamine in patients (Leier et al., 1982) as well as in rats (Buttrick et al., 1991) is a peripheral conditioning effect. Although an improved physical condition may have contributed to the slightly shorter latency in dobutamine-treated rats, all rats were capable of climbing out their cage (with the cage-mate in an adjacent cage) within $1 \mathrm{~min}$, and thus the much longer latency in the free exploration test represents a different motivation to climb out rather than a different motor response.

In the forced exploration test, when an anxiety component was present (Knardahl and Sagvolden, 1979), the lower interest in the environment, as evidenced by less exploratory behavior, was not altered by either treatment. However, captopril treatment normalized all aspects of increased anxiety - the greater preference for the relatively safe area of the open field, the corners; the lower number of visits into the least protected area, the middle (Dishman et al., 1988; Alonso et al., 1991; Unis et al., 1991); the less rearing and more scanning behavior, and the reduced locomotor activity, as shown by the shorter distance walked (line crossings) as well as by less time spent on walking (Alonso et al., 1991; Unis et al., 1991). In contrast, dobutamine had no effect on the increased anxiety.

Reduced social interest in non-treated infarcted rats was indicated by lower total social behavior, and more specifically by reduced approaching and social investigation, and more active avoidance of the other rat. This was not changed after dobutamine treatment, whereas captopril treatment increased social investigation, though at the expense of resting but not of non-social activities. The social interaction test in the rat has also been validated as a model of anxicty (File, 1981), and again only captopril treatment was able to alter social behavior. Anxiolytic effects of captopril in rats have been well studied in different situations (Barnes et al., 1989; Costall et al., 1990 ), including the social interaction test. Also clinical evidence for anxiolytic effects of captopril is growing (Oparil, 1993). Reduced anxiety has been found as an acute effect of captopril. The daily sessions began approximately $2 \mathrm{~h}$ after the beginning of the dark (= active) period. Probably even shortly before the beginning of the session the rats will have had captopril, because rats normally drink in the beginning of the dark period. We therefore cannot exclude that the behavioral changes that we observed could be atrributed to 'acute' effects of circulating captopril. Since chronic but not acute captopril improves hemodynamics in this rat model (Schoemaker et al., 1991a), the anxiolytic effect in the present study may thus represent a direct effect of captopril rather than the result of hemodynamic improvement. Dobutamine may even increase anxiety, though this is associated with acute administration (Mertes et al., 1993) and, hence, is not appropriate in the present study.

Interest in the environment, anxiety and social interest may be separate aspects of the changed behavior of rats with infarction since they can be affected separately. The lack of correlation between the results of the free exploration test and the results of other tests further supports this hypothesis.

In conclusion, in the present study we compared the effects of dobutamine and captopril, shown in previous studies to similarly improve hemodynamics, with regard to their effects on behavioral changes associated with a reduced quality of life of rats with heart failure. Although dobutamine seemed to restore the loss of interest in the environment, a sustained increase in anxiety may hamper rats to act accordingly in situations in which anxiety plays a role. In contrast, captopril treatment restored all behavioral changes associated with increased anxiety, a response which may be attributable to a direct effect of captopril. Thus, although the hemodynamic improvement obtained with dobutamine and captopril was expected to be similar, different aspects of the reduced quality of life were improved, indicating that there is no direct relationship between the two parameters. Since not only improved hemodynamics and/or prognosis may improve quality of life, but also improved quality of life may improve prognosis (psychological factors are associated with prognosis in each phase of myocardial infarction, Kenyon et al., 1991), the relationship between hemodynamics and prognosis, and quality of life requires further investigation. The presented behavioral tests, in combination with our previously described functional hemodynamic measurements, could provide a new basis to study treatment that improves the hemodynamic state as well as the quality of life.

\section{Acknowledgements}

The authors would like to thank Prof. J.M. Koolhaas and Prof. B. Bohus from the Department of Animal Physiology, University of Groningen, Netherlands, for their much appreciated contribution to the discussion of our findings.

\section{References}

Alonso, S.J., M.A. Castellano, D. Afonso and M. Rodriguez, 1991, Sex differences in behavioral despair: relationships between behavioral despair and open field activity, Physiol. Beh. 49, 69. 
Barnes, J.M., N.M. Bames, B. Costall, J. Coughlan, Z.P. Horovitz, M.E. Kelly, R.J. Naylor and D.M. Tomkins, 1989, ACE inhibition and cognition, in: Current advances in ACE Inhibition, eds. G.A. MacGregor and P.S. Sever (Churchill Livingstone, Edinburgh) p. 159.

Bamett, D.B., 1991, Assessment of quality of life, Am. J. Cardiol. 67, $41 \mathrm{C}$.

Blumenthal, J.A., L.G. Ekelund and C.F. Emery, 1990, Quality of life among hypertensive patients with a diuretic background who are taking atenolol and enalapril, Clin. Pharmacol. Ther. 48, 447.

Bluthé, R.M., R. Dantzer and K.W. Kelley, 1992, Effects of interleukin-1 receptor antagonist on the behavioral effects of lipopolysaccharide in rat, Brain Res. 573, 318.

Breckenridge, A., 1991, Angiotensin converting cnzym inhibitors and quality of life, Am. J. Hypertens. 4, 79s.

Bulpitt, C.J. and A.E. Fletcher, 1988, Measurement of the quality of life in congestive heart failure - influence of drug therapy, Cardiovasc. Drugs Ther. 2, 419.

Buttrick, P., C. Perla, A. Malhotra, D. Geenen, M. Lahorra and J. Scheuer, 1991, Effects of chronic dobutamine on cardiac mechanics and biochemistry after myocardial infarction in rats, Am. J. Physiol. 260, $\mathrm{H} 473$.

Consensus Trial Study Group, 1987, Effects of enalapril on mortality in severe congestive heart failure. Results of the cooperative North Scandinavian enalapril survival study (Consensus), New Engl. J. Med. $316,1429$.

Costall, B., A.M. Domeney, P.A. Gerrard, 7.P. Horovitz, M.E. Kelly, R.J. Naylor and D.M. Tomkins, 1990, Effects of captopril and SQ29,852 on anxiety-related behaviours in rodent and marmoset, Phamacol. Biochem. Behav. 36, 13.

Croog, S.H., S. Levine and B. Byron, 1986, The effects of antihypertensive treatment on the quality of life, New Engl. J. Med. 314, 1657.

Cushman, D.W., F.L. Wang, W.C. Fung, C.M. Harvey and J.M. DeForrest, 1989, Differentiation of angiotensin converting enzyme (ACE) inhibitors by their selective inhibition of ACE in physiological important target organs, Am. J. Hypertens. 2, 294.

Dantzer, R., R.-M. Bluthé and K.W. Kelley, 199I, Androgen-dependent vasopressinergic neurotransmission attenuates interleukin-1 induced sickness behavior, Brain Res. 557, 115.

Dishman, R.K., R.B. Armstrong, M.D. Delp, R.E. Graham and A.L. Dunn, 1988, Open field behavior is not related to treadmill performance in exercising rats, Physiol. Beh. 43, 541.

File, S.E., 1981, Animal tests of anxiety. Recent Adv. Neuropsychopharmacol. 31, 241.

Fishbein, M.C., D. MacLean and P.R. Maroko, 1978, Experimental myocardial infarction in the rat, Am. J. Pathol, 90, 57.

Guyatt, G.H., 1986, The treatment of heart failure. A methodological review of the literature, Drugs 32, 538.

Hodsman, G.P., M. Kohzuki, L.G. Howes, E. Sumithran, K. Tunoda and C.I. Johnston, 1988, Neurohumoral responses to chronic myocardial infarction in rats, Circulation 78, 376.

Just, H., H. Drexler, S.H. Taylor, J. Siegrist, G. Schulgen and M. Schumacher, 1993, Captopril versus digoxine in patients with coronary artery disease and mild heart failure. A prospective, double blind, placebo-controlled multicenter study, Herz 18 (Suppl. 1), 436.

Inoue, M., K. Kurahashi and M. Fujiwara, 1987, Noradrenaline turnover after left coronary artery ligation in rat heart, Eur. J. Pharmacol. 143, 251.

Kenyon, L.W., M.W. Ketterer and R.C. Preisman, 1991, Psychological factors relevant to the prehospital and in-hospital phase of acute myocardial infarction, Henry Ford Hosp. Med. J. 39, 176.

Knardahl, S. and T. Sagvolden, 1979, Open-field behavior of spontaneously hypertensive rats, Behav. Neural Biol. 27, 187.

Koolhaas, J.M., T. Schuurman and D.S. Fokkema, 1983, Social behavior of rats as a model for the psychophysiology of hypertension, in: The Biobehavioral Basis of Coronary Heart Disease, eds. T.M. Dembroski, T.H. Schmidt and G. Blumchen (Basel, Karger) p. 180.

Lamas, G.A. and M.A. Pfeffer, 1990, Left ventricular remodeling after acute myocardial infarction: clinical course and beneficial effects of angiotensin-converting enzyme inhibition, Prog. Cardiol. 121, 1194.

Lehman, M.N. and D.B. Adams, 1977, A statistical and motivational analysis of the social behaviors of the male laboratory rat, Behavior $61,238$.

Leier, C.V., P. Huss and R.P. Lewis, 1982, Drug induced conditioning in congestive heart failure, Circulation $65,1382$.

Liang, C.-S., L.G. Sherman, J.U. Doherty, K. Wellington, V.W. Lee and W.B. Hood Jr., 1984, Sustained improvement of cardiac function in patients with congestive heart failure after short-term infusion of dobutamine, Circulation 69, 113.

Mertes, H., S.G. Sawada, T. Ryan, D.S. Segar, R. Kovacs, J. Foltz and H. Feigenbaum, 1993, Symptoms, adverse effects, and complications associated with dobutamine stress echocardiography. Experience in 1118 patients, Circulation 88, 15.

Oldridge, N., G. Guyatt, N. Jones, J. Crowe, J. Singer, D. Feeny, R. McKelvie, J. Runions, D. Streiner and G. Torrance, 1991, Effects on quality of life with comprehensive rehabilitation after acute myocardial infarction, Am. J. Cardiol. 67, 1084.

Olson, E.B. and W.P. Morgan, 1982, Rat brain monoamine levels related to behavioral assessment, Life Sci. 30, 2095.

Olsson, G., J. Lubsen, G.-A. Van Es and N. Rehnqvist, 1986, Quality of life after myocardial infarction: effect of long-term metoprolol on mortality and morbidity, Br. Med. J. 292, 1491

Oparil, S., 1993, Antihypertensive therapy - efficacy and quality of life, New Engl. J. Med. 328, 959

Patel, K.P., P.L. Zhang and T.L. Krukoff, 1993, Alterations in brain hexokinase activity associated with heart failure in rats, Am. J. Physiol. 265, R923.

Pfeffer, J.M., M.A. Pfeffer and E. Braunwald, 1985, Influence of chronic captopril therapy on the infarcted left ventricle of the rat, Circ. Res. $57,84$.

Pfeffer, J.M., M.A. Pfeffer and E. Braunwald, 1987, Hemodynamic benefits and prolonged survival with long-term captopril therapy in rats with myocardial infarction and heart failure, Circulation 75 (Suppl. 1), 149.

Pfeffer, M.A. et al., on behalf of the SAVE Investigators, 1992, Effect of captopril on mortality and morbidity in patients with left ventricular dysfunction after myocardial infarction. Results of the Survival and Ventricular Enlargement Trial, New Engl. J. Med. 327, 669.

Rector, T.S. and J.N. Cohn, 1992, Assessment of patient outcome with the Minnesota I.iving with Heart Failure questionnaire: reliability and validity during a randomized, double-blind, placebo-controlled trial of pimobendan, Am. Heart J. 124, 1017.

Rector, T.S., G. Johnson, W.B. Dunkman, G. Daniels, L. Farrell, A. Hendrick, B. Smith and J.N. Cohn, 1993, Evaluation by patients with heart failure of the effects of enalapril compared with hydralazine plus isosorbide dinitrate on quality of life. V-HeFT II, Circulation 87 (Suppl.), VI71.

Roffman, D.S., M.M. Applefeld and W.R. Grove, 1985, Intermittent dobutamine hydrochloride infusions in outpatients with congestive heart failure, Clin. Pharmacol. 4, 195.

Schoemaker, R.G. and J.F.M. Smits, 1994, Behavioral changes following chronic myocardial infarction in rats, Physiol. Beh. 56, 585.

Schoemaker, R.G., J.J. Urquhart, J.J.M. Debets, H.A.J. Struyker Boudier and J.F.M. Smits, 1990, Acute hemodynamic effects of coronary artery ligation in conscious rats, Basic Res. Cardiol. 85, 9.

Schoemaker, R.G., J.J.M. Debets, H.A.J. Stnuyker Boudier and J.F.M. Smits, 1991a, Delayed but not immediate captopril therapy improves cardiac function in conscious rats following myocardial infarction, $\mathrm{J}$. Mol. Cell. Cardiol. 23, 187.

Schoemaker, R.G., J.J.M. Debets, H.A.J. Struyker Boudier and J.F.M. Smits, 1991b, Two weeks intermittent dobutamine therapy restores cardiac performance and inotropic responsiveness in conscious rats with heart failure, J. Cardiovasc. Pharmacol. 17, 949.

Singhvi, S.M., K.J. Kripalani, A.V. Dean, G.R. Keim, I.S. Kulesza, F.S. Meeker, J.J. Ross, J.M. Shaw and B.H. Migdalof, 1981, Absorption 
and bioavailability of captopril in mice and rats after administration by gavage and in the diet, J. Pharm. Sci. 70,885 .

Smits, J.F.M., J.P.M. Cleutjens, C. Van Krimpen, R.G. Schoemaker and M.J.A.P. Daemen, 1991, Cardiac remodeling in hypertension and following myocardial infarction: effects of arteriolar vasodilators, Basic Res. Cardiol. 86 (Suppl. 1), 133.

Smits, J.F.M., C. Van Krimpen, R.G. Schoemaker, J.P.M. Cleutjens and M.J.A.P. Daemen, 1992, Angiotensin II receptor blockade following myocardial infarction in rats: effects on hemodynamics, myocardial DNA-synthesis and interstitial collagen content. J. Cardiovasc. Pharmacol. 20, 772.

Sweet, C.S., C.T. Ludden, I.I. Stabilito, S.E. Emmert and J.F. Heyse, 1988, Beneficial effects of milrinone and enalapril on long-term survival of rats with healed myocardial infarction, Eur. J. Pharmacol. 147, 29.
Testa, M.A., R.B. Anderson, J.F. Nackley, N.K. Hollenberg and the Quality of Life Hypertension Study Group, 1993, Quality of life and anti-hypertensive therapy in man, New Engl. J. Med. 328, 907.

Unis, A.S., F. Petracca and J. Diaz, 1991, Somatic and behavioral ontogeny in three rat strains: preliminary observations of dopaminemediated behaviors and brain D-1 receptors, Prog. Neuro-Psychopharmacol. Biol. Psychiatry 15, 129.

Van Krimpen, C., J.F.M. Smits, J.P.M. Cleutjens, J.J.M. Debets, R.G. Schoemaker, H.A.J. Struyker Boudier, F.T. Bosman and M.J.A.P. Deamen, 1991, DNA synthesis in the non-infarcted cardiac interstitium after left coronary artery ligation in the rat; effects of captopril, J. Mol. Cell. Cardiol. 23, 1245. 